\title{
Epidemiology of Injuries in Belgium: Contribution of Hospital Data for Surveillance
}

\author{
Christelle Senterre, ${ }^{1}$ Alain Levêque, ${ }^{1}$ Lionel Di Pierdomenico, ${ }^{2}$ \\ Michèle Dramaix-Wilmet, ${ }^{1}$ and Magali Pirson ${ }^{2}$ \\ ${ }^{1}$ Research Center of Epidemiology, Biostatistics and Clinical Research, School of Public Health, \\ Université Libre de Bruxelles, Route de Lennik 808, CP 598, 1070 Brussels, Belgium \\ ${ }^{2}$ Research Center of Health Economics, Hospital's Management and Nursing, School of Public Health, \\ Université Libre de Bruxelles, Route de Lennik 808, CP 592, 1070 Brussels, Belgium
}

Correspondence should be addressed to Christelle Senterre; christelle.senterre@ulb.ac.be

Received 13 February 2014; Accepted 4 April 2014; Published 28 April 2014

Academic Editor: Claudia Slimings

Copyright (C) 2014 Christelle Senterre et al. This is an open access article distributed under the Creative Commons Attribution License, which permits unrestricted use, distribution, and reproduction in any medium, provided the original work is properly cited.

Objectives. Investigating injuries in terms of occurrences and patient and hospital stay characteristics. Methods. 17370 stays, with at least one E code, were investigated based on data from 13 Belgian hospitals. Pearson's chi-square and Kruskal-Wallis tests were used to assess the variations between distributions of the investigated factors according to the injury's types. Results. Major injuries were accidental falls, transport injuries, and self-inflicted injuries. There were more men in the transport injuries group and the accidental falls group was older. For the transport injuries, there were more arrivals with the support of a mobile intensive care unit and/or a paramedic intervention team and a general practitioner was more implicated for the accidental falls. In three-quarters of cases, it was a primary diagnostic related to injury and poisoning which was made. The median length of stay was nearly equal to one week and for accidental falls, this value is three times higher. The median cost, from the social security point of view, for all injuries was equal to $€ 1377$ and there was a higher median cost within the falls group. Conclusion. This study based on hospitals data provides important information both on factors associated with and on hospital costs generated by injuries.

\section{Introduction}

In Belgium, as in other countries all over the world, injuries remain a public health problem. In 2009, in the European Union, mortality due to external causes was equal to 30 deaths for 100000 inhabitants, with higher values in Belgium than in its neighboring countries: $36.8 / 100000$ versus 31.0/100000 in France, 29.9/100000 in Luxembourg, 19.8/100000 in Germany, and 16.4/100000 in the Netherlands [1]. Still in 2009, without considering the age groups, suicide and transport injuries were among the top ten causes of death in Belgium, with a proportionality mortality ratio (PMR) of $1.9 \%$ ( 7 th place in the ranking) and $1.0 \%$ (10th place in the ranking), respectively. In the 15-24-year age group, suicide and transport injuries were the two first leading causes of death, with a PMR of $36.7 \%$ and $22.9 \%$, respectively. The situation was nearly the same in the 25-44-year age group (suicide PMR equal to $22.9 \%$, 1st place in the ranking, and $11.6 \%$ for the transport PMR, 3rd place in the ranking) [2]. Next to this high mortality, there is significant morbidity and also an important burden of these injuries. In the European region, according to the Global Burden of Disease report road traffic injuries are in the 6th place in the ranking of the leading causes of burden diseases with 3.7 million of disability-adjusted life year (DALY's), corresponding to $2.4 \%$ of total DALY's; selfinflicted injuries are in the 10th place with 3.1 million DALY's, corresponding to $2.0 \%$ percent of total DALY's [3]. Generally, mortality is well documented, especially for certain type of injuries (e.g., traffic injuries), but there is lack of information about the morbidity. However, several types of data sources are available for injury morbidity surveillance, for example, population based survey data and emergency department data or hospital data [4]. Within the European region, injuries represent an estimated number of 7200000 hospital admissions, 34800000 emergency department attendances, and 18600000 other medical treatments [5]. According to 
the summary of injury statistics for the years 2008-2010 published by the European Association for Injury Prevention and Safety Promotion (EuroSafe) [6], in Belgium, the estimated percentage of injury related to hospital discharge is equal to $10 \%$. Although hospitalized injuries represent a small proportion of nonfatal injuries, they are generally more severe and are associated with higher medical and treatment cost than those who are not treated in hospital, and because patients admitted to hospital usually have longer stays than those treated in the emergency department, hospital inpatient records usually contain more detailed and accurate information about the diagnosis of injury than emergency department visit records $[4,7,8]$.

In Belgium, the Minimal Clinical Dataset is a standardized and concise summary of the patient's medical record that general hospitals are required to register since 1990. The registration has the objectives to identify needs for hospital equipment, to define the standards of qualitative and quantitative recognition of hospitals and their services, to organize the funding of hospitals, to determine policy on the exercise of the art of healing, and to define epidemiological policy [9]. In the early 2000s, a published ministerial circular has strongly encouraged the registration of the codes $\mathrm{E}$ [10]. To our knowledge, no epidemiological studies have investigated specifically the distribution of E codes in the database, nor patient characteristics, and even less the cost associated with the hospitalization. So the objectives of our study were to investigate these E codes, based on the more available recent data, in terms of occurrences, patient characteristics, and hospital stay characteristics.

\section{Methods}

2.1. Cases' Selection. These analyses were performed with the 2010 data from 13 Belgian hospitals, which are included in the PACHA project, a project focused on the analysis of stays and pathologies cost. These hospitals are either private or public. In 2010, the total of inpatient stays from this sample represented $11.4 \%$ of all Belgian inpatient stays. On the 473426 available stays (inpatient stays and day care stays), only hospital stays with at least one external cause (E codes) were selected. There were up to $3 \mathrm{E}$ codes for some case files (Figure 1). Data were coded according to the ninth revision of the International Classification of Diseases, clinical modification (ICD-9-CM), so the E codes' groups taken into account in this study were presented in Table 1 [11]. As in the EUROCOST project [12, 13]-concerning the cost estimation of injury-related hospital admissions in European countries-and as in Meerding and colleagues [14] study on the costs of injuries in the Netherlands, we have not considered the following E codes: "misadventures to patients during surgical and medical care" [E870-E876], "surgical and medical procedures as the cause of abnormal reaction of patient or later complication, without mention of misadventure at the time of procedure" [E878-E879], and "drugs and medicinal and biological substances causing adverse effects in therapeutic use" [E930-E949].

In the ICD-9-CM, causes and place of occurrence were found in the same chapter, so we have first differentiated, on
TABLE 1: Codes of the external causes of injury in the ICD-9-CM taken into account in this study.

\begin{tabular}{|c|c|}
\hline & Causes \\
\hline$(\mathrm{E} 800-\mathrm{E} 848)$ & Transport injuries \\
\hline$(\mathrm{E} 850-\mathrm{E} 858)$ & $\begin{array}{l}\text { Accidental poisoning by drugs, medicinal } \\
\text { substances, and biologicals }\end{array}$ \\
\hline$(\mathrm{E} 860-\mathrm{E} 869)$ & $\begin{array}{l}\text { Accidental poisoning by other solid and liquid } \\
\text { substances, gases, and vapors }\end{array}$ \\
\hline (E880-E888) & Accidental falls \\
\hline$(\mathrm{E} 890-\mathrm{E} 899)$ & Accidents caused by fire and flames \\
\hline (E900-E909) & $\begin{array}{l}\text { Accidents due to natural and environmental } \\
\text { factors }\end{array}$ \\
\hline (E910-E915) & $\begin{array}{l}\text { Accidents caused by submersion, suffocation, } \\
\text { and foreign bodies }\end{array}$ \\
\hline (E916-E928) & Other accidents \\
\hline (E950-E959) & Suicide and self-inflicted injury \\
\hline (E960-E969) & $\begin{array}{l}\text { Homicide and injury purposely inflicted by } \\
\text { other persons }\end{array}$ \\
\hline (E970-E978) & Legal intervention \\
\hline (E980-E989) & $\begin{array}{l}\text { Injury undetermined whether accidentally or } \\
\text { purposely inflicted }\end{array}$ \\
\hline (E990-E999) & Injury resulting from operations of war \\
\hline$(\mathrm{E} 979)$ & Terrorism \\
\hline \multirow[t]{2}{*}{ (E929) } & Late effects of accidental injury \\
\hline & Place of occurrence \\
\hline$(\mathrm{E} 849.0)$ & Home accidents \\
\hline$(\mathrm{E} 849.1)$ & Farm accidents \\
\hline$(\mathrm{E} 849.2)$ & Mine and quarry accidents \\
\hline$(\mathrm{E} 849.3)$ & $\begin{array}{l}\text { Accidents occurring in industrial places and } \\
\text { premises }\end{array}$ \\
\hline$(\mathrm{E} 849.4)$ & $\begin{array}{l}\text { Accidents occurring in place for recreation and } \\
\text { sport }\end{array}$ \\
\hline$(\mathrm{E} 849.5)$ & Street and highway accidents \\
\hline$(\mathrm{E} 849.6)$ & Accidents occurring in public building \\
\hline$(\mathrm{E} 849.7)$ & Accidents occurring in residential institution \\
\hline$(\mathrm{E} 849.8)$ & Accidents occurring in another specified place \\
\hline (E849.9) & Accidents occurring in unspecified place \\
\hline
\end{tabular}

one hand, the causes and, on the other hand, the places of injuries. Because of this absence of differentiation between place and cause, all the patients have not both code for the cause and another one for the place (Figure 1). Besides that, for the management of the stays with more than one cause we have created, for the extraction of a "main" external cause, a decision algorithm based on the gravity's perception. For example, if a patient had both a code for an accidental fall and another one, like transport injury [E800-E848] or accidental poisoning by drugs, medicinal substances, and biologicals [E850-E858] or suicide and self-inflicted injury [E950-E959] or another homicide and injury purposely inflicted by other persons [E960-E969], we have taken into account those second codes. In other words, if a person attempts suicide with drugs and falls after having ingested the drugs, it is more important to consider the suicide attempt than the fall. 


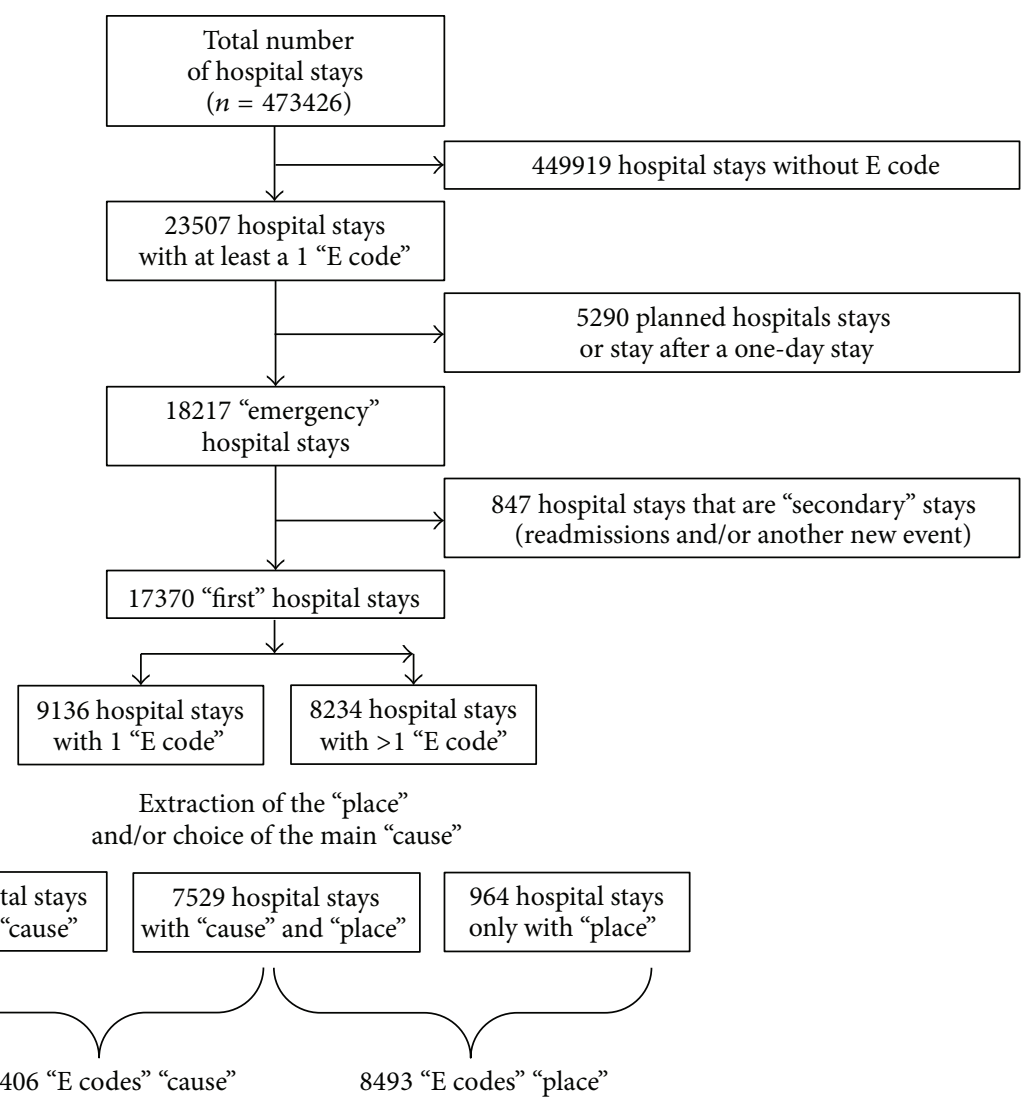

FIGURE 1: Flow chart of the selection of the stays.

2.2. Associated Factors. The other variables taken into account have been chosen to try to follow the patient from its arrival to its discharge. The demographic characteristics of the patients were gender and age and we also have information about the moment (month and day), the type and the initiative of the hospital's admissions, the primary diagnosis that justifies the hospitalization, the stays description (in terms of care units), the type of discharge, the patient's destination, the cause of death, the type and the length of stay, and finally the cost incurred from the social security point of view.

2.2.1. Type of Admission. Based on the preexisting categories, we have regrouped the type of admissions in 4 categories that may already reflect certain gravity of the injury: 1: admissions through the emergency department (ED) without ambulance; 2: admissions through the ED with an ambulance; 3: admissions through the ED with an ambulance and also with the intervention of a MICU, mobile intensive care unit, and/or a PIT, paramedic intervention unit; and finally 4: unplanned admission, meaning emergency hospitalization not through the emergency department.

2.2.2. Primary Diagnosis. It is defined as the affection which, upon medical examination, proved to be the main cause of patient's admission. For the description of this primary diagnosis, we have used the chapter headings of the ICD9-CM classification (Table 2) and we have detailed more the chapter concerning the injury and poisoning (Table 3).
2.2.3. Stays Description. The different services were the emergency unit, the one-day unit, the intensive care unit, the burn unit, the diagnostic and surgical care unit, the diagnostic and medical care unit, the geriatric unit, the pediatric unit, the neuropsychiatric unit, the specialized unit for the treatment and rehabilitation (with cardiopulmonary affections, musculoskeletal affections, neurological diseases, palliative care, polychronic diseases, and psychogeriatric affections), and finally the obstetric and neonatal unit.

During the stays, patients could change, one or more times, service according to the evolution of their health status. We therefore have investigated up to three consecutive services, with a focus on the passages by the intensive care unit or by the specialized units for the treatment and rehabilitation. Focus was made because a stay in one of these services may reflect certain gravity of the health status.

2.2.4. Type of Discharge, Patient's Destination, and Cause of Death. Based on the preexisting categories, we have regrouped the type of discharge in 5 categories. Two categories were related to the hospital's discharge with or without medical advice and the 3 others were related to a transfer to another place: 1: for specialized care, 2: for reeducation, or 3: for logistic reasons (e.g., for financial problems). The patient's destination was taken into account because this variable contains relevant information in terms of patient's redirecting to psychiatric homes/hospitals or to elderly homes. The other variable's categories were the domicile, another hospital, or all 
TABLE 2: Chapter headings of the ICD-9-CM classification.

\begin{tabular}{|c|c|}
\hline$(001-139)$ & Infectious and parasitic diseases \\
\hline$(140-239)$ & Neoplasms \\
\hline$(240-279)$ & $\begin{array}{l}\text { Endocrine, nutritional, and metabolic diseases } \\
\text { and immunity disorders }\end{array}$ \\
\hline$(280-289)$ & Diseases of the blood and blood-forming organs \\
\hline$(290-319)$ & Mental disorders \\
\hline$(320-389)$ & Diseases of the nervous system and sense organs \\
\hline$(390-459)$ & Diseases of the circulatory system \\
\hline$(460-519)$ & Diseases of the respiratory system \\
\hline$(520-579)$ & Diseases of the digestive system \\
\hline$(580-629)$ & Diseases of the genitourinary system \\
\hline$(630-676)$ & $\begin{array}{l}\text { Complications of pregnancy, childbirth, and } \\
\text { puerperium }\end{array}$ \\
\hline$(680-709)$ & Diseases of the skin and subcutaneous tissue \\
\hline$(710-739)$ & $\begin{array}{l}\text { Diseases of the musculoskeletal system and } \\
\text { connective tissue }\end{array}$ \\
\hline$(740-759)$ & Congenital anomalies \\
\hline$(780-799)$ & Symptoms, signs, and ill-defined conditions \\
\hline$(800-999)$ & Injury and poisoning \\
\hline$(\mathrm{V} 01-\mathrm{V} 89)$ & $\begin{array}{l}\text { Factors influencing health status and contact } \\
\text { with health services }\end{array}$ \\
\hline
\end{tabular}

other possible destinations such as jail or a boarding school. By the way of these two variables it was also possible to know if the patient was dead during their stay. The cause of death was reported in one of the fields of the patient file. It is important to note that the reported cause of death was the one that appears on the death certificate and that this cause is, for the nonnatural deaths, the circumstances of the accident (or the place of injuries if no type of injuries was reported) unless there was a morbid condition underlying (e.g., the neoplasms and the circulatory diagnoses). This death can be natural or nonnatural, so for this variable, there was coexistence of codes related to diseases and codes related to external causes (Tables 2 and 3$)$.

2.2.5. Type, Length, and Cost of Stays. The type of stays can provide first information about the gravity, because a patient who only stays for a day hospitalization is probably less affected than a patient who stays as an inpatient. Furthermore, patients in the case of the day hospitalization, day surgery, or outpatient emergency have a length of stay equal to one day, so they are not taken into account when it is the question of the estimation of mean or median length of stay (reported in days). The estimation of the costs borne by social security (reported in euros) was also only based on the inpatient stays and the costs were broken down into costs resulting from medical procedures, from pharmaceutical products, and from day lump sums. The percentage of each of these 3 specific costs in relation to the whole cost was also calculated.

2.3. Statistical Analyses. Categorical variables were described with both absolute and relative frequencies and the variations between these distributions according to the different groups
TABLE 3: Subchapter injury and poisoning of the ICD-9-CM classification.

\begin{tabular}{|c|c|}
\hline$(800-804)$ & Fracture of skull \\
\hline$(805-809)$ & Fracture of neck and trunk \\
\hline$(810-819)$ & Fracture of upper limb \\
\hline$(820-829)$ & Fracture of lower limb \\
\hline$(830-839)$ & Dislocation \\
\hline$(840-848)$ & $\begin{array}{l}\text { Sprains and strains of joints and adjacent } \\
\text { muscles }\end{array}$ \\
\hline$(850-854)$ & $\begin{array}{l}\text { Intracranial injury, excluding those with skull } \\
\text { fracture }\end{array}$ \\
\hline$(860-869)$ & Internal injury of thorax, abdomen, and pelvis \\
\hline$(870-879)$ & Open wounds of head, neck, and trunk \\
\hline$(880-887)$ & Open wounds of upper limb \\
\hline$(890-897)$ & Open wounds of lower limb \\
\hline$(900-904)$ & Injury to blood vessels \\
\hline$(905-909)$ & $\begin{array}{l}\text { Late effects of injuries, poisonings, toxics effects, } \\
\text { and other external causes }\end{array}$ \\
\hline$(910-919)$ & Superficial injury \\
\hline$(920-924)$ & Contusion with intact skin surface \\
\hline$(925-929)$ & Crushing injury \\
\hline$(930-939)$ & Effects of foreign body entering through orifice \\
\hline$(940-949)$ & Burns \\
\hline$(950-957)$ & Injury to nerves and spinal cord \\
\hline$(958-959)$ & $\begin{array}{l}\text { Certain traumatic complications and unspecified } \\
\text { injuries }\end{array}$ \\
\hline$(960-979)$ & $\begin{array}{l}\text { Poisoning by drugs and medicinal and biological } \\
\text { substances }\end{array}$ \\
\hline (980-989) & $\begin{array}{l}\text { Toxic effects of substances chiefly nonmedicinal } \\
\text { as a source }\end{array}$ \\
\hline$(990-995)$ & Other and unspecified effects of external causes \\
\hline (996-999) & $\begin{array}{l}\text { Complications of surgical and medical care, not } \\
\text { elsewhere classified }\end{array}$ \\
\hline
\end{tabular}

of injuries were assessed using Pearson's chi-square test in accordance with the Cochran guidelines cited by Altman [15] ( $80 \%$ of the cells in the table should have expected frequencies greater than 5 and all cells should have expected frequencies greater than 1). Because of the skewness of the quantitative variables, the median and the 25th and the 75th percentiles were reported and the Kruskal-Wallis nonparametric test was used to assess the variation between the distributions of these variables according to the different groups of injuries. The significance level for all tests was 0.05 and all statistical analyses were performed using Stata/SE 12.0 for Windows (TX: StataCorp LP).

\section{Results}

3.1. E Codes Observed. Table 4 shows that the three major groups of injuries observed were accidental falls [E880-E888] (58.2\%), transport injuries [E800-E848] (11.2\%), and suicide and self-inflicted injuries [E950-E959] (10.6\%). According to these observations the next results would be presented 
TABLE 4: Causes and place of occurrence.

\begin{tabular}{|c|c|c|c|}
\hline Causes & $(n=16406)$ & Places of occurrence & $(n=8493)$ \\
\hline (E800-E848) & $1841(11.2)$ & (E849.0) & $3578(42.1)$ \\
\hline (E850-E858) & $303(1.8)$ & (E849.1) & $9(0.1)$ \\
\hline (E860-E869) & $191(1.2)$ & $(\mathrm{E} 849.2)$ & $4(<0.1)$ \\
\hline (E880-E888) & $9555(58.2)$ & (E849.3) & $167(2.0)$ \\
\hline (E890-E899) & $53(0.3)$ & (E849.4) & $365(4.3)$ \\
\hline (E900-E909) & $232(1.4)$ & (E849.5) & $1140(13.4)$ \\
\hline (E910-E915) & $187(1.1)$ & (E849.6) & $290(3.4)$ \\
\hline (E916-E928) & $1474(9.0)$ & $(\mathrm{E} 849.7)$ & $1263(14.9)$ \\
\hline (E950-E959) & $1745(10.6)$ & (E849.8) & $199(2.3)$ \\
\hline (E960-E969) & $448(2.7)$ & (E849.9) & $1478(17.4)$ \\
\hline (E970-E978) & $1(<0.1)$ & & \\
\hline (E980-E989) & $235(1.4)$ & & \\
\hline (E990-E999) & $1(<0.1)$ & & \\
\hline (E979) & $1(<0.1)$ & & \\
\hline (E929) & $139(0.9)$ & & \\
\hline
\end{tabular}

Data are $n(\%)$.

on one hand for all stays and on the other hand for these three groups. Concerning the place of occurrence, there was obviously a correlation with the causes: home accidents [E849.0] (42.1\%), accidents occurring in a residential institution [E849.7] (14.9\%), and street and highway accidents [E849.5] (13.4\%) were the major places observed.

3.2. Demographic Characteristics of the Patients. There were significantly more men in the transport injuries group than in the two other groups (66.7\% versus $39.3 \%$ and $37.0 \%$, resp.) and the patients in the accidental falls were older than those in the two other groups (median age equal to 74 years versus 32 years and 41 years, resp.) (Table 5 ).

3.3. Moment, Type, and Initiative of the Hospital's Admissions. Figures 2 and 3 show the repartition of all injuries according to the weekday and month of the year. For all injuries, there were more admissions on Mondays (15.7\%) and Tuesdays (14.7\%) than on other weekdays (from $13.8 \%$ on Wednesdays to $14.1 \%$ on Sundays). The same trend was roughly observed for the falls, but there were significantly $(P<0.001)$ more admissions for traffic injuries on Saturdays and Sundays (17.9\% and 17.4\%) and more admissions for suicide and selfinflicted injuries on Sundays (16.8\%) and Mondays (16.2\%). For the month of admissions, the percentages were nearly the same for each month (from $7.4 \%$ in February to 9.3\% in December) for all injuries, but the repartition was significantly $(P<0.001)$ different between traffic injuries, accidental falls, and self-inflicted injuries. The highest proportions of admissions for traffic injuries were observed between May (10.8\%) and August (10.3\%). For accidental falls, December (10.6\%) was the most observed, and finally for self-inflicted injuries, higher proportions were observed in January (9.6\%) and July (9.5\%).

Regarding the type of admission, there were significantly $(P<0.001)$ more arrivals through the emergency department with the support of a mobile intensive care unit and/or a paramedic intervention team in the group of the transport injuries than in the accidental falls and suicide groups (36.4\% versus $10.3 \%$ and $23.5 \%$, resp.). Relating to the person at the initiative of the admission, the general practitioner was more implicated in the case of an accidental fall (21.9\% versus $2.5 \%$ and $7.0 \%$, resp.), while a third party was implicated in nearly half the situations of transport injuries and a little more than forty percent of the self-inflicted injuries (47.4\% and $43.3 \%$ versus $27.9 \%$, resp.). It was also observed that a not inconsiderable proportion of admissions were due to the initiative of the patient (Table 6).

3.4. Primary Diagnosis That Justifies the Hospitalization. Table 7 showed that for all injuries, in three-quarters of cases (74.6\%), it was a diagnostic related to injury and poisoning [800-999] which was made, and this proportion was significantly different $(P<0.001)$ between the three studied groups, with a lower proportion in the accidents' falls group relative to the transport injuries and the self-inflicted injuries (72.2\% versus $93.1 \%$ and $90.0 \%$, resp.). In the accidental falls group, there were diseases of the circulatory system and in the self-inflicted injuries group mental disorders were found in a higher proportion than in the other groups. If we look in more detail to the injury and poisoning diagnosis group, half of it consisted of fractures: $22.8 \%$ for fractures of the lower limbs [820-829], 16.6\% for fractures of the upper limbs [810819], 8.2\% for fractures of the neck and the trunk [805-809], and finally $3.3 \%$ from fracture of the skull. In the transport injuries group, besides the nearly fifty percent of fractures (17.7\% for the neck and trunk, $17.1 \%$ for the upper limbs, and $14.4 \%$ for the lower limbs), there were almost fifth (18.1\%) of intracranial injuries [850-854]. In the accidental falls, seven cases of ten were also fractures: $36.1 \%$ for the lower limbs, $22.9 \%$ for the upper limbs, and $10.2 \%$ for the neck and the trunk. Finally, in the self-inflicted injuries group, ninetyone percent were poisoning by drugs and medicinal and biological substances [960-979] accounting for $84.1 \%$ and $6.9 \%$ were toxic effects of substances chiefly nonmedicinal as a source [980-989] (Table 8).

3.5. Stays Description. Figure 4 shows that two-thirds of the 17370 patients have stayed in a diagnostic and surgical care unit (C) $(34.4 \%)$ or in a diagnostic and medical care unit (D) (36.7\%) on their arrivals, and a little less than five percent (3.9\%) were directly admitted to the intensive care unit. For 409 of the 17370 patients, the stay was extended by a passage in the intensive care unit. Therefore, $6 \%$ of all patients remained at least one day in an intensive care unit. After the stay in the intensive care unit, $28.6 \%$ patients have left the hospital. Among the patients who were returned to one other service, after the stay in the intensive care unit, 31.3\% were returned to a C unit and $31.3 \%$ other were returned to a $\mathrm{D}$ unit. Figure 5 shows that, regarding the specialized units for the treatment and the rehabilitation, 616 patients have gone through these units after a first ward, with 412 for the musculoskeletal affections. Finally, 85.3\% percent of these 616 patients were discharged from the hospital after their stays in one of the six specialized units. 
TABLE 5: Gender and age of the patients for all injuries and according to the 3 major E codes' groups.

\begin{tabular}{|c|c|c|c|c|c|}
\hline & All injuries & Transport & Falls & Suicide & $P$ value \\
\hline Gender & $n=17370$ & $n=1841$ & $n=9555$ & $n=1745$ & $<0.001$ \\
\hline Male & $8305(47.8)$ & $1228(66.7)$ & $3756(39.3)$ & $645(37.0)$ & \\
\hline Female & $9065(52.2)$ & $613(33.3)$ & $5799(60.7)$ & $1100(63.0)$ & \\
\hline Age (years) & $57(33-80)$ & $32(20-48)$ & $74(52-84)$ & $41(28-50)$ & $<0.001$ \\
\hline
\end{tabular}

Data are $n(\%)$ and median (p25-p75).

TABLE 6: Information about admissions for all injuries and according to the 3 E codes' groups.

\begin{tabular}{|c|c|c|c|c|c|}
\hline & All injuries & Transport & Falls & Suicide & $P$ value \\
\hline Type of admission, through & $n=17370$ & $n=1841$ & $n=9555$ & $n=1745$ & $<0.001$ \\
\hline ED, without ambulance & $7711(44.4)$ & $554(30.1)$ & $4059(42.5)$ & $609(34.9)$ & \\
\hline ED, with ambulance & $6705(38.6)$ & $587(31.9)$ & $4353(45.6)$ & $715(41.0)$ & \\
\hline ED, with ambulance and MICU and/or PIT & $2645(15.2)$ & $670(36.4)$ & $988(10.3)$ & $410(23.5)$ & \\
\hline Emergency hospitalization & $309(1.8)$ & $30(1.6)$ & $155(1.6)$ & $11(0.6)$ & \\
\hline At the initiative of & $n=17340$ & $n=1838$ & $n=9539$ & $n=1745$ & $<0.001$ \\
\hline His/her own initiative & $7223(41.7)$ & $788(42.9)$ & $3760(39.4)$ & $791(45.4)$ & \\
\hline A specialist & $1093(6.3)$ & $113(6.2)$ & $589(6.2)$ & $40(2.3)$ & \\
\hline His/her insurer & $26(0.2)$ & $4(0.2)$ & $12(0.1)$ & $5(0.3)$ & \\
\hline A third party & $5430(31.3)$ & $871(47.4)$ & $2664(27.9)$ & $754(43.3)$ & \\
\hline His/her general practitioner & $2960(17.1)$ & $45(2.5)$ & $2087(21.9)$ & $122(7.0)$ & \\
\hline A doctor on call & $608(3.5)$ & $17(0.9)$ & $427(4.5)$ & $31(1.8)$ & \\
\hline
\end{tabular}

ED: emergency department, MICU: mobile intensive care unit, and PIT: paramedic intervention unit.

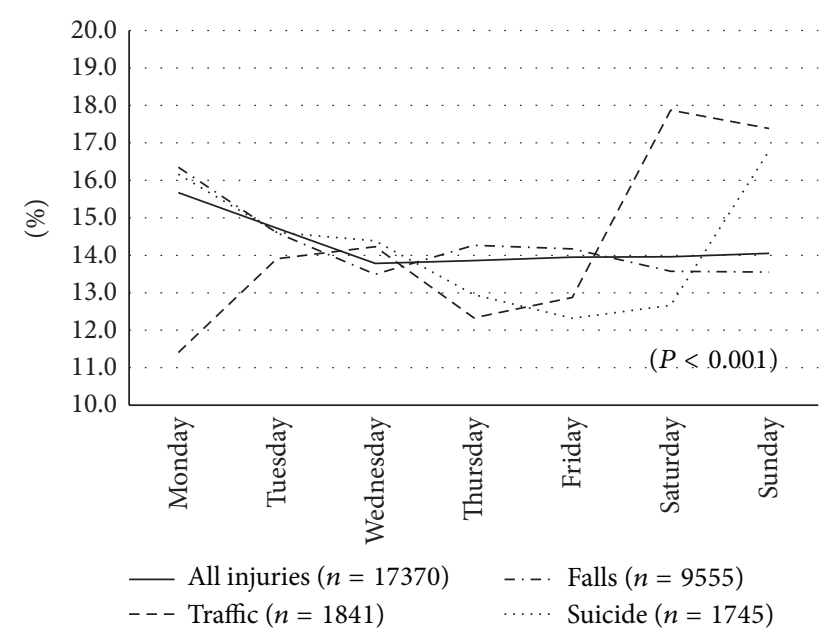

FIGURE 2: Variation of the proportions of injuries according to the weekdays.

3.6. Type of Discharge, Patient's Destination, and Cause of Death. Seven hundred and twenty-six patients of the entire sample have lost life at hospital, with more than half of the deaths $(n=490,67.5 \%)$ concerning patients admitted for accidental falls [E880-E888]. We have also observed 50 deaths (6.9\%) concerning patients admitted for accidents caused by submersion, suffocation, and foreign bodies [E910-E915], 46 deaths (6.3\%) concerning patients admitted for transport injuries [E800-E848], and 22 deaths (3.0\%) concerning patients admitted for suicide and self-inflicted injuries [E950-E959]. Sixty-eight deaths are related to

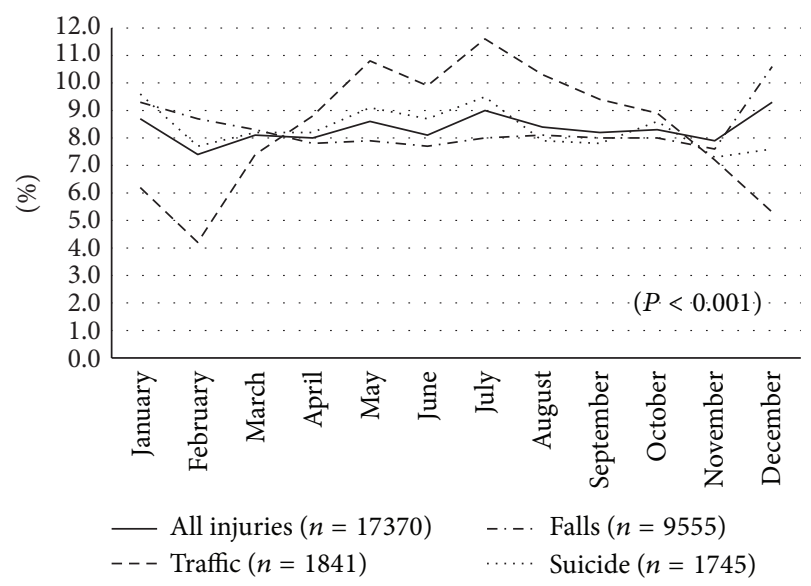

FIGURE 3: Variation of the proportions of injuries according to the months of the year.

patients for whom we only have the place of occurrence, and the two major places reported were the residential institution [E849.7] for 45 cases (6.2\%) and the home for 17 cases of death $(2.3 \%)$ (data not shown). Therefore, the proportion of death was significantly higher in the group of accidental falls than in the other two groups $(5.2 \%$ versus $2.5 \%$ and $1.3 \%$, resp.) (Table 9).

About the type of discharge, the proportion of transfer for specialized care was higher in the self-inflicted group (5.8\% versus $3.6 \%$ and $2.4 \%$, resp.) and the proportion of discharge without medical consent was also higher in this 
TABLE 7: Primary diagnosis (ICD-9-CM) for all injuries and according to the 3 major E codes' groups.

\begin{tabular}{lcccc}
\hline & All injuries & Transport & Falls & Suicide \\
\hline Primary diagnosis & $n=17370$ & $n=1841$ & $n=9555$ & $n=1745$ \\
$(001-139)$ & $153(0.9)$ & $1(<0.1)$ & $91(1.0)$ & $2(0.1)$ \\
$(140-239)$ & $123(0.7)$ & - & $75(0.8)$ & $2(0.1)$ \\
$(240-279)$ & $211(1.2)$ & $1(<0.1)$ & $33(0.4)$ & - \\
$(280-289)$ & $52(0.3)$ & - & $315(3.3)$ & $126(7.2)$ \\
$(290-319)$ & $576(3.3)$ & $13(0.7)$ & $312(3.3)$ & $7(0.4)$ \\
$(320-389)$ & $440(2.5)$ & $15(0.8)$ & $574(6.0)$ & $1(<0.1)$ \\
$(390-459)$ & $870(5.0)$ & $15(0.8)$ & $230(2.4)$ & $6(0.3)$ \\
$(460-519)$ & $476(2.7)$ & $5(0.3)$ & $129(1.4)$ & $4(0.2)$ \\
$(520-579)$ & $280(1.6)$ & $1(<0.1)$ & $114(1.2)$ & $3(0.2)$ \\
$(580-629)$ & $209(1.2)$ & $1(<0.1)$ & $8(<0.1)$ & $1(<0.1)$ \\
$(630-676)$ & $23(0.1)$ & $5(0.3)$ & $22(0.2)$ & $1(<0.1)$ \\
$(680-709)$ & $87(0.5)$ & $4(0.2)$ & $277(2.9)$ & $2(0.1)$ \\
$(710-739)$ & $379(2.2)$ & $21(1.1)$ & $3(<0.1)$ & - \\
$(740-759)$ & $3(<0.1)$ & - & $216(2.3)$ & $10(0.6)$ \\
$(780-799)$ & $361(2.1)$ & $18(1.0)$ & $6903(72.2)$ & $1570(90.0)$ \\
$(800-999)$ & $12955(74.6)$ & $1714(93.1)$ & $109(1.1)$ & $9(0.5)$ \\
$($ V01-V89) & $172(1.0)$ & $27(1.5)$ & $<0.001^{*}$
\end{tabular}

Data are $n(\%) .{ }^{*} P$ value from a dichotomous comparison of (800-999) versus all the other primary diagnoses.

TABLE 8: Injury and poisoning diagnosis (ICD-9-CM) for all stays and according to the 3 major E codes' groups.

\begin{tabular}{|c|c|c|c|c|}
\hline & All injuries & Transport & Falls & Suicide \\
\hline Injury and poisoning & $n=12955$ & $n=1714$ & $n=6903$ & $n=1570$ \\
\hline$(800-804)$ & $426(3.3)$ & $89(5.2)$ & $223(3.2)$ & $9(0.6)$ \\
\hline$(805-809)$ & $1058(8.2)$ & $304(17.7)$ & $703(10.2)$ & $2(0.1)$ \\
\hline$(810-819)$ & $2156(16.6)$ & $293(17.1)$ & $1577(22.9)$ & $2(0.1)$ \\
\hline$(820-829)$ & $2949(22.8)$ & $246(14.4)$ & $2491(36.1)$ & $6(0.4)$ \\
\hline$(830-839)$ & $293(2.3)$ & $54(3.2)$ & $184(2.7)$ & $2(0.1)$ \\
\hline$(840-848)$ & $226(1.7)$ & $33(1.9)$ & $101(1.5)$ & - \\
\hline$(850-854)$ & $1185(9.2)$ & $311(18.1)$ & $693(10.0)$ & $5(0.3)$ \\
\hline$(860-869)$ & $243(1.9)$ & $100(5.8)$ & $88(1.3)$ & $7(0.5)$ \\
\hline$(870-879)$ & $313(2.4)$ & $57(3.3)$ & $165(2.4)$ & $11(0.7)$ \\
\hline$(880-887)$ & $593(4.6)$ & $30(1.8)$ & $40(0.6)$ & $53(3.4)$ \\
\hline$(890-897)$ & $128(1.0)$ & $31(1.8)$ & $37(0.5)$ & $1(<0.1)$ \\
\hline$(900-904)$ & $19(0.2)$ & $2(0.1)$ & $1(<0.1)$ & $7(0.5)$ \\
\hline$(905-909)$ & $3(<0.1)$ & - & $3(<0.1)$ & - \\
\hline$(910-919)$ & $42(0.3)$ & $6(0.4)$ & $5(<0.1)$ & $2(0.1)$ \\
\hline$(920-924)$ & $528(4.1)$ & $125(7.3)$ & $294(4.3)$ & $7(0.5)$ \\
\hline$(925-929)$ & $36(0.3)$ & $5(0.3)$ & $4(<0.1)$ & - \\
\hline (930-939) & $65(0.5)$ & - & $1(<0.1)$ & - \\
\hline$(940-949)$ & $173(1.3)$ & $2(0.1)$ & $5(<0.1)$ & $3(0.2)$ \\
\hline$(950-957)$ & $41(0.3)$ & $2(0.1)$ & $11(0.2)$ & $4(0.3)$ \\
\hline (958-959) & 201 (1.6) & $19(1.1)$ & $138(2.0)$ & $8(0.5)$ \\
\hline$(960-979)$ & $1644(12.7)$ & - & $23(0.3)$ & $1321(84.1)$ \\
\hline$(980-989)$ & $309(2.4)$ & $1(<0.1)$ & $14(0.2)$ & $108(6.9)$ \\
\hline (990-995) & $125(1.0)$ & $2(0.1)$ & $15(0.2)$ & $12(0.8)$ \\
\hline$(996-999)$ & 199 (1.5) & $2(0.1)$ & $87(1.3)$ & - \\
\hline
\end{tabular}

Data are $n(\%)$. 

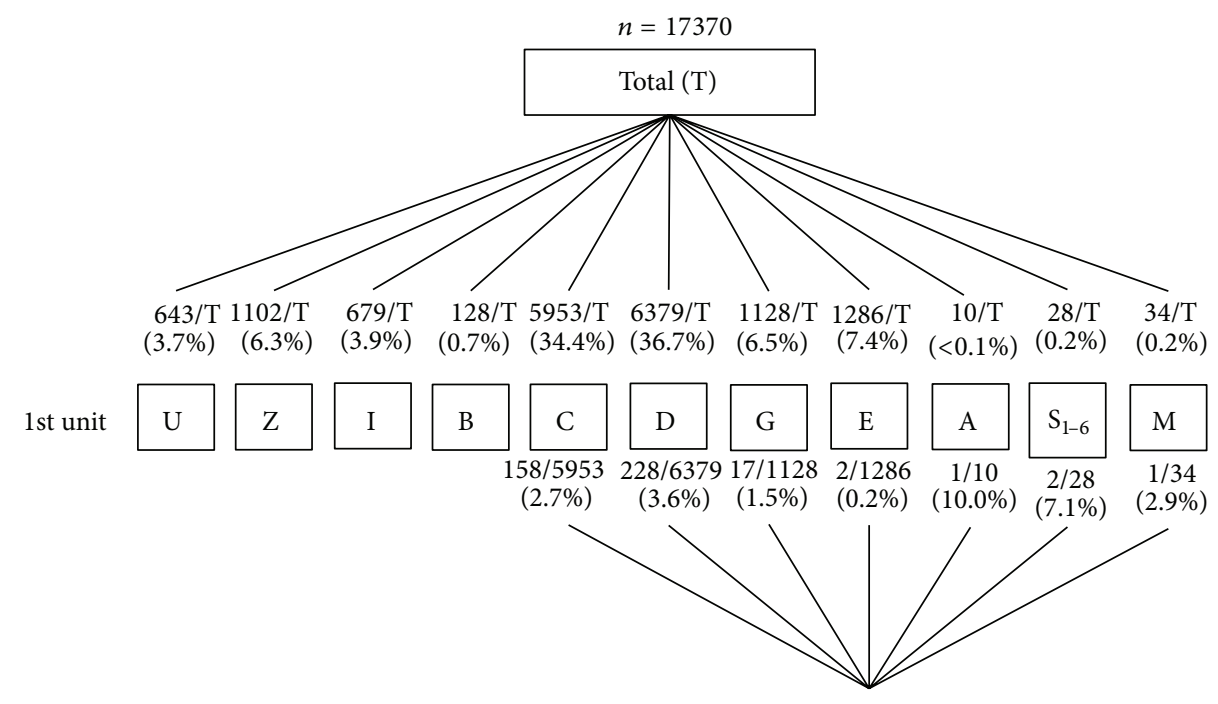

2nd unit

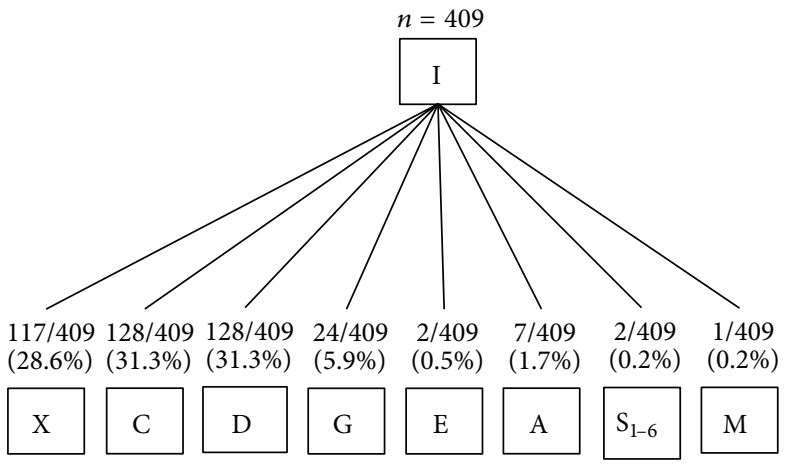

$\mathrm{U}$ : emergency unit

$\mathrm{Z}$ : one-day unit

I: intensive care unit

B: burn unit

C: diagnostic unit and surgical treatment

D: diagnostic unit and medical treatment

\author{
G: geriatric unit \\ E: pediatric unit \\ A: neuropsychiatric unit \\ S: specialized unit for the treatment and rehabilitation \\ M: obstetric and neonatal unit \\ $\mathrm{X}$ : exit
}

FIGURE 4: Stays description with a focus on the intensive care unit as the second unit.

TABLE 9: Vital status, discharge, and destination for all injuries and according to the 3 major E codes' groups.

\begin{tabular}{|c|c|c|c|c|c|}
\hline & All injuries & Transport & Falls & Suicide & $P$ value \\
\hline Vital status & $n=17349$ & $n=1839$ & $n=9544$ & $n=1741$ & $<0.001$ \\
\hline Death & $726(4.2)$ & $46(2.5)$ & $490(5.1)$ & $22(1.3)$ & \\
\hline Type of discharge & $n=16623$ & $n=1793$ & $n=9054$ & $n=1719$ & $<0.001$ \\
\hline On medical advice & $15664(94.2)$ & $1692(94.4)$ & $8605(95.0)$ & $1469(85.5)$ & \\
\hline Without consent & $315(1.9)$ & $22(1.2)$ & $87(1.0)$ & $138(8.0)$ & \\
\hline Transfer for specialized care & $448(2.7)$ & $65(3.6)$ & $214(2.4)$ & $100(5.8)$ & \\
\hline Transfer for reeducation & $167(1.0)$ & $17(0.8)$ & $126(1.4)$ & $9(0.5)$ & \\
\hline Transfer for logistic reasons & $29(0.2)$ & $0(0.0)$ & $22(0.2)$ & $3(0.2)$ & \\
\hline Type of destination & $n=16603$ & $n=1790$ & $n=9050$ & $n=1714$ & $<0.001$ \\
\hline Domicile & $14271(86.0)$ & $1664(93.0)$ & $7345(81.2)$ & $1555(90.7)$ & \\
\hline Another hospital & $534(3.2)$ & $92(5.1)$ & $329(3.6)$ & $32(1.9)$ & \\
\hline Elderly homes & $1452(8.8)$ & $13(0.7)$ & $1254(13.9)$ & $12(0.7)$ & \\
\hline Psychiatric homes/hospitals & $207(1.2)$ & $2(0.1)$ & $59(0.6)$ & $98(5.7)$ & \\
\hline Others & $139(0.8)$ & $19(1.1)$ & $63(0.7)$ & $17(1.0)$ & \\
\hline
\end{tabular}

Data are $n(\%)$. 


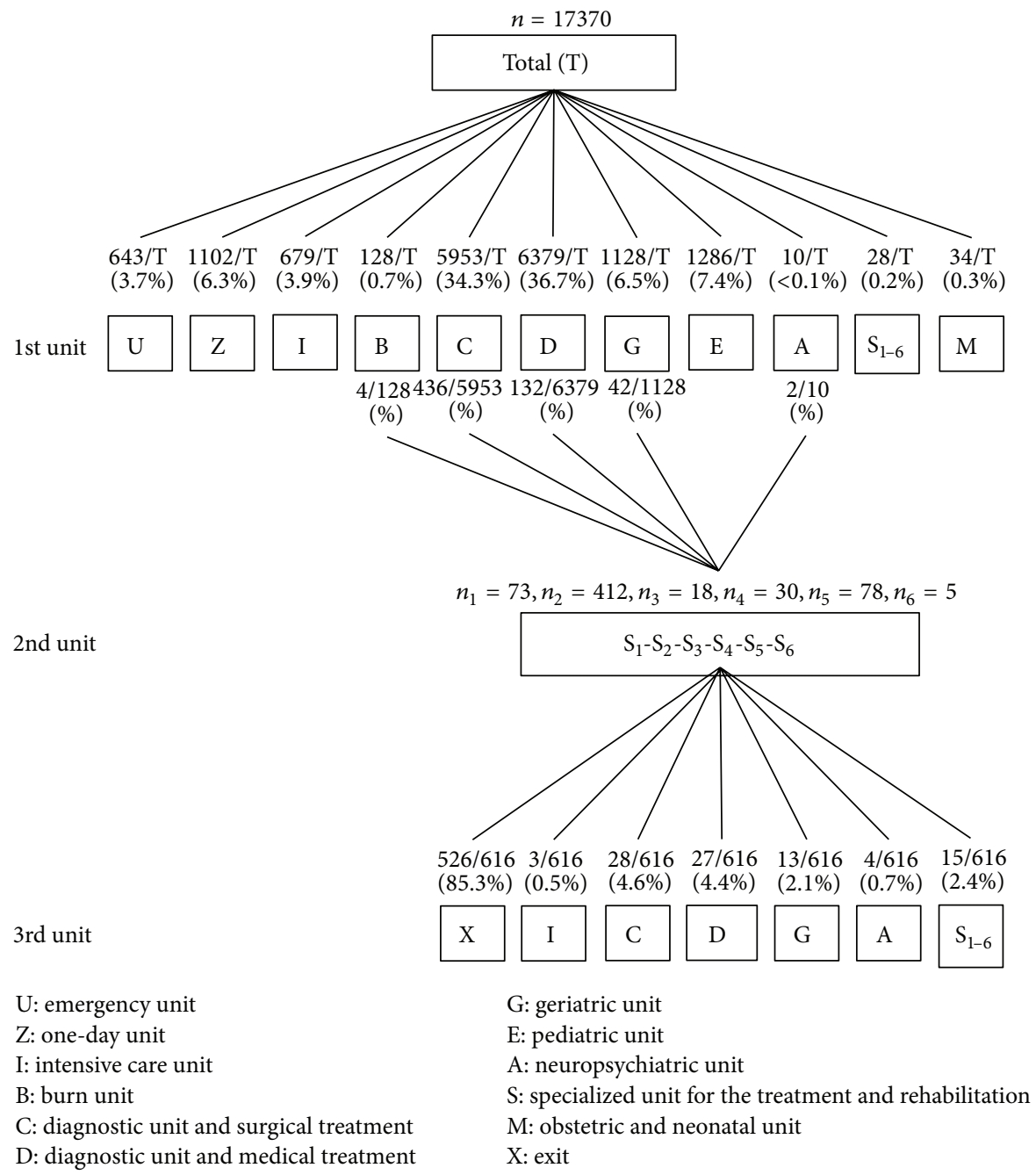

FIGURE 5: Stays description with a focus on the specialized unit for the treatment and the rehabilitation as the second unit.

group than the other two (8.0\% versus $1.2 \%$ and $1.0 \%$, resp.). Concerning the destination after the discharge, a large part of the patients returned to their home, but in the accidental falls group nearly $14 \%$ went to elderly homes and in the selfinflicted injuries groups 5.7\% went to psychiatric structures (Table 9).

If we look in more detail to the causes of death, we observe that $31.6 \%$ in the transport group, $17.5 \%$ in the accidental falls group, and $29.4 \%$ in the self-inflicted injuries group were directly related to the type of injuries which have led to the admission, and for another part it was the injury and poisoning cause which has been mentioned $(23.7 \%, 12.5 \%$, and $41.2 \%$ in the three groups, resp.). The other major cause of death observed was a disease of the circulatory system both for the transport injuries group and for the accidental falls group $(36.8 \%$ and $27.6 \%$, resp.) (Table 10$)$.

3.7. Type, Length of Stay, and Cost Incurred. Concerning the hospital stays, the inpatient stays were the most observed. According to the three groups investigated the proportion of inpatients was significantly higher in the suicide group ( $94.7 \%$ versus $91.3 \%$ and $92.4 \%$, resp.). Overall, the median length of stay was nearly equal to one week (6 days) and in the accidental falls group, this value was at least three times higher than in the two other groups ( 9 days versus 3 days and 2 days, resp.). The median cost borne by social security for all injuries was equal to $€ 1376.6$, with little more than twenty-five percent of the total inpatient stays being with a cost higher than $€ 2500$. There was also a higher median cost within the accidental falls group compared to the transport injuries group and the self-inflicted injuries group $(€ 1760.4$ versus $€ 112.6$ and $€ 669.5$, resp.). On the whole cost, the medical procedures were significantly proportionally highest for the accidental falls group and for the transport injuries group than for the suicide group $(68.0 \%$ and $67.3 \%$ versus $58 \%$ ); and the costs of the pharmaceutical procedures were significantly proportionally highest for the suicide group than for the transport injuries group and the accidental falls group (19.5\% versus $13.6 \%$ and $10.7 \%$, resp.) (Table 11$)$.

\section{Discussion}

To our knowledge, in Belgium, no epidemiological studies have recently investigated specifically the distribution of $\mathrm{E}$ 
TABLE 10: Death's causes for all injuries and according to the 3 major E codes' groups.

\begin{tabular}{lcccc}
\hline & All injuries & Transport & Falls & Suicide \\
\hline Cause of death & $n=573^{*}$ & $n=38$ & $n=384$ & $n=17$ \\
(E800-E848) & $12(2.1)$ & $12(31.6)$ & - & - \\
$($ E850-E858) & $1(0.2)$ & - & - & - \\
$($ E878-E879) & $1(0.2)$ & - & $1(0.3)$ & - \\
$($ E880-E888) & $68(11.9)$ & - & $67(17.5)$ & - \\
$($ E890-E899) & $2(0.4)$ & - & $1(0.3)$ & - \\
$($ E910-E915) & $7(1.2)$ & - & $1(0.3)$ & - \\
$(\mathrm{E} 950-E 959)$ & $5(0.9)$ & - & - & $5(29.4)$ \\
$(001-139)$ & $15(2.6)$ & - & $8(2.1)$ & - \\
$(140-239)$ & $66(11.5)$ & - & $47(12.2)$ & $1(5.9)$ \\
$(240-279)$ & $5(0.9)$ & - & $4(1.0)$ & - \\
$(280-289)$ & $1(0.2)$ & - & $1(0.3)$ & - \\
$(290-319)$ & $3(0.5)$ & - & $3(0.8)$ & - \\
$(320-389)$ & $11(1.9)$ & $1(2.6)$ & $4(1.0)$ & $1(5.9)$ \\
$(390-459)$ & $156(27.2)$ & $14(36.8)$ & $106(27.6)$ & $1(5.9)$ \\
$(460-519)$ & $64(11.1)$ & - & $42(10.9)$ & - \\
$(520-579)$ & $26(4.5)$ & - & $16(4.2)$ & - \\
$(580-629)$ & $9(1.6)$ & - & $6(1.6)$ & - \\
$(630-676)$ & $0(0.0)$ & - & - & - \\
$(680-709)$ & $1(0.2)$ & - & $1(0.3)$ & - \\
$(710-739)$ & $3(0.5)$ & - & $2(0.5)$ & - \\
$(780-799)$ & $35(6.1)$ & $2(5.3)$ & $26(6.8)$ & $2(11.8)$ \\
$(800-999)$ & $82(14.3)$ & $9(23.7)$ & $48(12.5)$ & $7(41.2)$ \\
\hline Data $)$ & - & - &
\end{tabular}

Data are $n(\%) .{ }^{*}$ In the 726 deaths, there were 153 missing causes.

codes in the Minimal Clinical Summary database, nor patient characteristics, and even less the cost associated with the hospitalization.

4.1. E Codes Observed and Demographic Characteristics of the Patients. As for mortality, transport injuries and selfinflicted injuries were also within the major groups observed $[13,16]$. Regarding the gender, more men were present in the transport injuries group but there were more women in the self-inflicted injuries group. This observation is consistent with the known risk factors: women have more attempts on their lives than men [17]. Women were also more present in the accidental falls group. This group is also the one in which patients are older. These two demographic characteristics were equally found in other studies $[18,19]$.

4.2. Moment, Type, and Initiative of the Hospital's Admissions. Our study showed that there were on the whole-and it is the same for the accidental falls group-more admissions on Mondays and Tuesdays than on other weekdays, but there were more admissions for traffic injuries on Saturdays and Sundays and more admissions for suicide and self-inflicted injuries on Sundays and Mondays. It was the same trend as that reported not only by Hawton and van Heeringen [17] in their International Handbook of Suicide and Attempted Suicide, but also by the studies of Beauchamp and colleagues [20] or Colman and colleagues [21].
Regarding the type of admission, there were, for the transport injuries group, more arrivals through the emergency department with the support of a mobile intensive care unit and/or a paramedic intervention team than in the other groups, and relating to the person at the initiative of the admission, the general practitioner was more implicated in the case of an accidental fall. These observations might inform about the seriousness of the traffic injuries, as a mobile intensive care unit's intervention involves "intensive care," while for accidental falls, the intervention of a general practitioner may be explained by the fact that the patients in this group are older.

4.3. Primary Diagnosis That Justifies the Hospitalization. In three-quarters of cases, a diagnosis related to injury and poisoning was reported, with a lower proportion in the accidental falls in which there were more diseases of the circulatory system and in the self-inflicted injuries group, where more mental disorders were found. This difference, in the accidental falls group, must probably be explained by the fact that, in this group, these older patients have more preexisting chronic conditions; the observation in the self-inflicted group is consistent with the literature which reports that there is a significant link between the mental health and the suicidal behaviors $[17,22,23]$. Regarding the injury and poisoning diagnosis group, fractures were the most common diagnosis observed in the accidental falls group and in the traffic injuries group, with a nonnegligible part of intracranial injuries in this last group. These observations were also made in other studies [12, $14,24]$. Finally, in the self-inflicted injuries group, poisoning by drugs and medicinal and biological substances was the most frequent diagnosis observed. This is consistent with the fact that women, who are more represented in this group, were known to choose less violent methods than men, with a predilection for ingesting drugs [22].

4.4. Stays Description. A little more than five percent of the whole patients were remaining at least one day in an intensive care unit. In absence of real information about the severity of the injury-as in other European countries, the data do not include, for example, the AIS (abbreviated injury scale)the seriously injured patients could not be distinguished even if a stay in the intensive care unit is an important indication of the gravity [12]. Regarding the specialized units for the treatment and the rehabilitation, 616 patients have gone through these units after a first ward, with 412 for the musculoskeletal affections. This observation is consistent with the fact that a large number of patients who have had a stay in the specialized units must be linked with the fact that there was an important proportion of limbs fracture. These stays in specialized units might give an idea about the future disabilities of these injured patients, but only a longitudinal follow-up could confirm these disabilities $[13,16]$.

4.5. Type of Discharge, Patient's Destination, and Cause of Death. The proportion of death was higher in the group of accidental falls, with a lower proportion of related death to this fall which has led to the admission. It is certainly correlated with the older age of the patients in this group 
TABLE 11: Type, length, and cost of stays for all stays and according to the 3 major E codes' groups.

\begin{tabular}{|c|c|c|c|c|c|}
\hline & Total & Transport & Falls & Suicide & $P$ value \\
\hline Type of stay & $n=17370$ & $n=1841$ & $n=9555$ & $n=1745$ & $<0.001$ \\
\hline Inpatient & $15626(90.0)$ & $1680(91.3)$ & $8825(92.4)$ & $1653(94.7)$ & \\
\hline Day surgery & $528(3.0)$ & $18(1.0)$ & $165(1.7)$ & $6(0.3)$ & \\
\hline Day hospitalisation & $1097(6.3)$ & $136(7.4)$ & $515(5.4)$ & $84(4.8)$ & \\
\hline Outpatient emergency & $119(0.7)$ & $7(0.4)$ & $50(0.5)$ & $2(0.1)$ & \\
\hline Length of stay ${ }^{*}$ & $n=15626$ & $n=1680$ & $n=8825$ & $n=1653$ & $<0.001$ \\
\hline Stay (days) & $6(2-15)$ & $3(2-8)$ & $9(3-19)$ & $2(2-5)$ & \\
\hline Cost (euros) $)^{*}$ & $n=15174$ & $n=1617$ & $n=8619$ & $n=1616$ & \\
\hline Total cost & $1376.6(751.4-2584.5)$ & $1112.6(698.8-2091.8)$ & $1760.4(1006.8-3049.6)$ & $669.5(564.3-1031.9)$ & $<0.001$ \\
\hline Medical procedures & $949.6(449.4-1704.4)$ & $777.4(414.7-1456.7)$ & $1210.4(665.6-1958.7)$ & $382.3(298.4-685.9)$ & $<0.001$ \\
\hline Pharmaceutical products & $150.3(129.2-200.3)$ & $141.3(126.0-180.5)$ & $160.0(132.5-217.1)$ & $130.0(120.6-150.2)$ & $<0.001$ \\
\hline Day lump sums & $192.7(139.0-315.7)$ & $167.2(123.2-236.0)$ & $212.1(145.7-353.1)$ & $157.1(120.8-198.7)$ & $<0.001$ \\
\hline Percentages of the total cost* & $n=15174$ & $n=1617$ & $n=8619$ & $n=1616$ & \\
\hline Medical procedures & $66.1(55.5-74.7)$ & $67.3(55.6-75.9)$ & $68.0(57.9-75.6)$ & $58.0(52.0-67.3)$ & \\
\hline Pharmaceutical products & $12.5(7.9-19.2)$ & $13.6(8.7-19.7)$ & $10.7(7.0-16.2)$ & $19.5(13.9-23.3)$ & \\
\hline Day lump sums & $16.1(9.8-23.1)$ & $15.3(8.8-23.1)$ & $14.4(8.9-20.9)$ & $22.1(16.4-26.9)$ & \\
\hline
\end{tabular}

* Only for the inpatients. Data are $n(\%)$ and median (p25-p75).

and with the presence of other diseases as observed in other studies [23]. For the alive patients in this group, a lot of patients returned to their home, and for a little more than one out of ten, the return was toward an elderly home. According to our data we cannot know if the patients were already in this type of structure before their admissions.

In a little less than half of the self-inflicted cases it was the injury and poisoning cause which has been mentioned as the cause of death and; for the alive patients in this group, the proportion of transfer for specialized care and to psychiatric structures as well as of discharge without medical consent was higher than in the other two groups. This need for specific psychiatric care and the problem of unauthorized discharge are clearly documented in suicidology theory $[17,22]$.

4.6. Type, Length of Stay, and Cost Incurred. The median length of stay was nearly equal to one week and was similar to that observed by McKenzie and colleagues [25] in their study. In the accidental falls group, this value is at least three times higher. Scuffham and colleagues [23] have also observed a longer stay for the older elderly patients. Concerning the cost, we have observed that a little more than a quarter of the total inpatient stays have been supported by the social security cost higher than $€ 2500$. In the accidental falls group, the median cost was higher than in the other groups; this observation is again correlated with the fact that these patients were older, have other diseases, and have longer hospital stays $[12,13$, 23]. Therefore, that is why, on the whole cost, the medical procedures and the day lump sums were proportionally highest in this group. On the other hand, it was the drug cost that was significantly the most important part of the total cost in the suicide group.

Even if it is difficult to compare our costs' results with other studies because of the data's content in our dataset, our observations contributed to the better knowing of the burden of injuries in Belgium. But it is also important to note that taking only into account the hospital costs is (sometimes) only to consider the "tip of the iceberg" because injuries lead (sometimes) to long-term follow-up costs, as shown in the study of Meerding [14] and colleagues who have investigated the costs of injuries based not only on hospital care but also on nursing home care and rehabilitative services.

4.7. Quality of the Data. Although there is a ministerial circular that strongly encourages the registration of the codes E when they are present, we have observed that there were shortcomings regarding the encoded information: some cases have only the injury's cause or only the place of occurrence. We have also observed that there is an important utilization of the ". 9 " code; codes corresponding to the "other accident"/"unspecified cause" and "other place"/"unspecified place" and these codes are generally not useful to researchers because they lack details. These observations were also made in other studies [26-28]. According to McKenzie and colleagues [25] it is essential that clinicians and coders alike be aware of the documentation and coding problems related to the capture of cause-injury data. Another problem is the existence of more than one code of cause. In our study we have elaborated a decision's algorithm, but without knowing the hierarchy of the event, we maybe have made some misinterpretations. In their study, Scuffham and colleagues [23] present the example of a fall occurring on the road which will be coded as traffic injuries. Lawrence and colleagues [27] complete with the fact that "a fall should be E coded only if it causes an injury that is medically treated. If a patient falls down as a result of an illness or poisoning, but does not sustain an injury from the fall, then the fall should not be coded in the patient's record. But we often found records $\mathrm{E}$ coded as falls where the only diagnoses are heart conditions."

In this paper, we have made the choice to not take into account the hospital readmissions. Other authors have made 
the same choice with the justification that, to consider those events, in a simple way, do not allow overestimation of the impact of injuries $[12-14,18]$. Nevertheless, the study of the patients with more than one admission during a year must be really interesting in terms of understanding the repetitive injuries, in terms of investigations of complications/disabilities correlated with the initial injury, and also in terms of incurred costs [18]. It will be also interesting to investigate the costs related to other used health services (e.g., outpatients visits, general practitioner visits, outpatient physical therapy, and home care), as Meerding and colleagues have done [14].

\section{Conclusion}

Our study, the first of such kind in Belgium, has documented the occurrences, the related diagnosis, and the nonnegligible cost for the social security of all types of hospitalized injuries, specifically for three majors groups: the traffic injuries, the suicide and self-inflicted injuries, and finally the accidental falls. In this last group, we have also shown that because these injuries affect the elderly, there is a significant comorbidity which must be also taken into consideration.

Finally, despite the fact that injuries remain an important public health, especially in Belgium, and despite the European Union initiative, our country is not in the list of members' states that have committed to participate to the Joint Action on Monitoring Injuries in Europe (JAMIE) initiative, even it is obvious that the hospital sector provides the best setting for collecting information as this piece of information is related to the more severe cases, and information can be obtained easily on a large number of cases at low cost [5]. The total hospital costs generated by injuries indicate the relative importance of injuries in the healthcare sector as a whole and may be useful in convincing politicians of the importance of preventing injuries and investing in trauma care, and ideally costs and burden of injury should be analyzed in a combined perspective $[12,13]$.

\section{Conflict of Interests}

The authors declare that there is no conflict of interests regarding the publication of this paper.

\section{References}

[1] World Health Organization Regional Office for Europe, "The European health for all database," http://data.euro.who.int/ hfadb/.

[2] Scientific Institute of Public Health, "Standardized Procedures for Mortality Analysis," https://www.wiv-isp.be/epidemio/ spma/.

[3] World Health Organization, "The global burden of disease: 2004 update," 2008, http://www.who.int/healthinfo/global_ burden_disease/2004_report_update.

[4] G. Li and S. Baker, Injury Research: Theories, Methods and Approaches, Springer, New York, NY, USA, 2012.

[5] W. Rogmans, "Joint action on monitoring injuries in Europe (JAMIE)," Archives of Public Health, vol. 70, article 19, 2012.
[6] European Association for Injury Prevention and Safety Promotion (EuroSafe), "Injuries in the European Union, Report on injury statistics 2008-2010," 2013, http://ec.europa.eu/health/ data_collection/docs/idb_report_2013_en.pdf.

[7] S. Boufous and A. Williamson, "Reporting of the incidence of hospitalised injuries: numerator issues," Injury Prevention, vol. 9, no. 4, pp. 370-375, 2003.

[8] J. M. Horan and S. Mallonee, "Injury surveillance," Epidemiologic Reviews, vol. 25, pp. 24-42, 2003.

[9] Federal Public Service Health, Food Chain Safety and Environment, "Organization of the Health Cares," http://www.sante .sante.belgique.be/eportal/Healthcare/index.htm.

[10] Circulaire aux organes de gestion des hopitaux. Codage obligatoire des codes E dans le résumé clinique Minimum, 2003.

[11] Centers for Disease Control and Prevention, "The International Classification of Diseases, Ninth Revision, Clinical Modification (ICD-9-CM)," http://www.cdc.gov/nchs/icd/icd9cm.htm.

[12] S. Polinder, W. J. Meerding, M. E. van Baar, H. Toet, S. Mulder, and E. F. van Beeck, "Cost estimation of injury-related hospital admissions in 10 European countries," The Journal of Trauma, vol. 59, no. 6, pp. 1283-1291, 2005.

[13] S. Polinder, W. J. Meerding, S. Mulder et al., "Assessing the burden of injury in six European countries," Bulletin of the World Health Organization, vol. 85, no. 1, pp. 27-34, 2007.

[14] W. J. Meerding, S. Mulder, and E. F. Van Beeck, "Incidence and costs of injuries in The Netherlands," European Journal of Public Health, vol. 16, no. 3, pp. 271-277, 2006.

[15] D. Altman, Practical Statistics for Medical Research, Chapman and Hall, London, UK, 1991.

[16] E. G. Krug, G. K. Sharma, and R. Lozano, "The global burden of injuries," The American Journal of Public Health, vol. 90, no. 4, pp. 523-526, 2000.

[17] K. Hawton and K. van Heeringen, The International Handbook of Suicide and Attempted Suicide, John Wiley and Sons, Chichester, UK, 2000.

[18] B. Jansson, M. Stenbacka, A. Leifman, and A. Romelsjö, "A small fraction of patients with repetitive injuries account for a large portion of medical costs," European Journal of Public Health, vol. 14, no. 2, pp. 161-167, 2004.

[19] P. Corso, E. Finkelstein, T. Miller, I. Fiebelkorn, and E. Zaloshnja, "Incidence and lifetime costs of injuries in the United States," Injury Prevention, vol. 12, no. 4, pp. 212-218, 2006.

[20] G. Beauchamp, M. Ho, and S. Yin, "Variation in suicide occurence by day and during major american holidays," The Journal of Emergency Medicine, 2014.

[21] I. Colman, N. Yiannakoulias, D. Schopflocher, L. W. Svenson, R. J. Rosychuk, and B. H. Rowe, "Population-based study of medically treated self-inflicted injuries," Canadian Journal of Emergency Medicine, vol. 6, no. 5, pp. 313-320, 2004.

[22] R. Maris, A. Berman, and M. Silveman, Comprehensive Textbook of Suicidology, The Guildford Press, New York, NY, USA, 2000.

[23] P. Scuffham, S. Chaplin, and R. Legood, "Incidence and costs of unintentional falls in older people in the United Kingdom," Journal of Epidemiology and Community Health, vol. 57, no. 9, pp. 740-744, 2003.

[24] D. Bowley, "World Wide Wounds," 2002, http://www.worldwidewounds.com/2002/october/Bowley/Patterns-Of-InjuryMVAS.html.

[25] K. McKenzie, L. F. Harding, S. M. Walker, J. E. Harrison, E. L. Enraght-Moony, and G. S. Waller, "The quality of cause-ofinjury data: where hospital records fall down," Australian and 
New Zealand Journal of Public Health, vol. 30, no. 6, pp. 509513, 2006.

[26] J. A. Langlois, J. S. Buechner, E. A. O’Connor, E. Q. Nacar, and G. S. Smith, "Improving the E coding of hospitalizations for injury: do hospital records contain adequate documentation?" The American Journal of Public Health, vol. 85, no. 9, pp. 12611265, 1995.

[27] B. A. Lawrence, T. R. Miller, H. B. Weiss, and R. S. Spicer, "Issues in using state hospital discharge data in injury control research and surveillance," Accident Analysis and Prevention, vol. 39, no. 2, pp. 319-325, 2007.

[28] K. McKenzie, E. Enraght-Moony, L. Harding, S. Walker, G. Waller, and L. Chen, "Coding external causes of injuries: problems and solutions," Accident Analysis and Prevention, vol. 40, no. 2, pp. 714-718, 2008. 


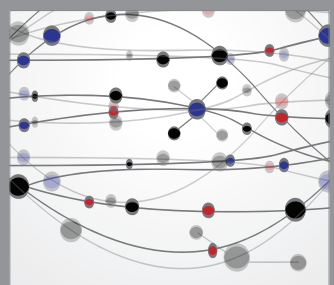

The Scientific World Journal
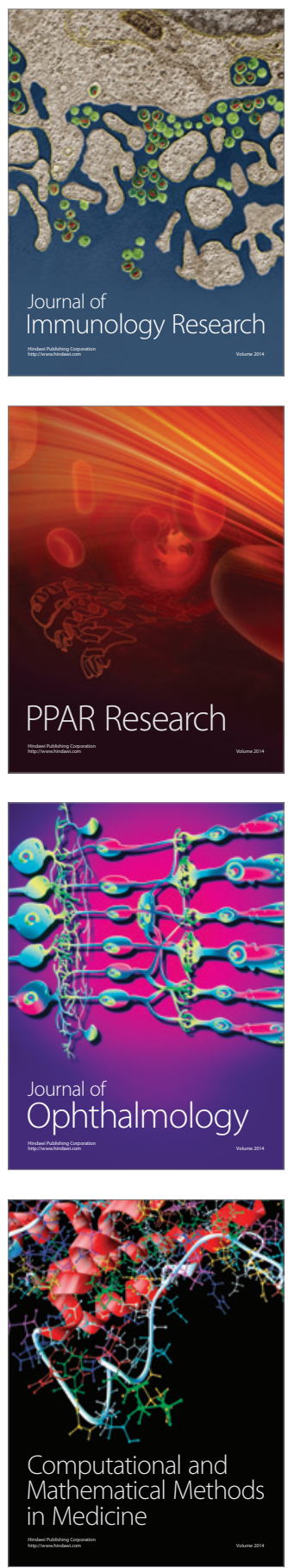

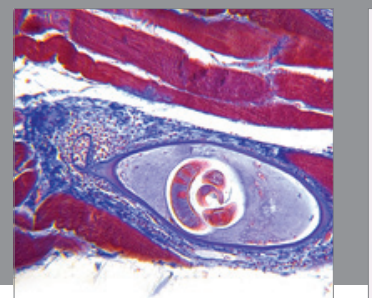

Gastroenterology

Research and Practice
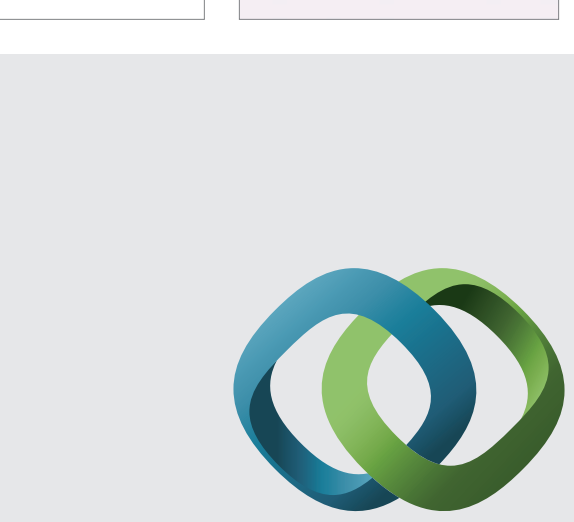

\section{Hindawi}

Submit your manuscripts at

http://www.hindawi.com
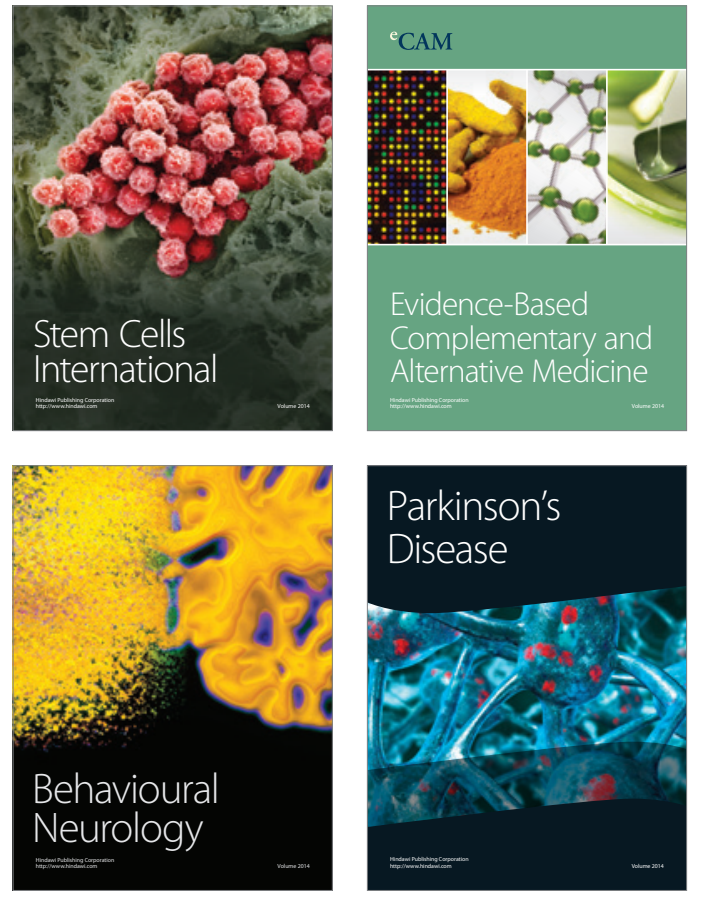
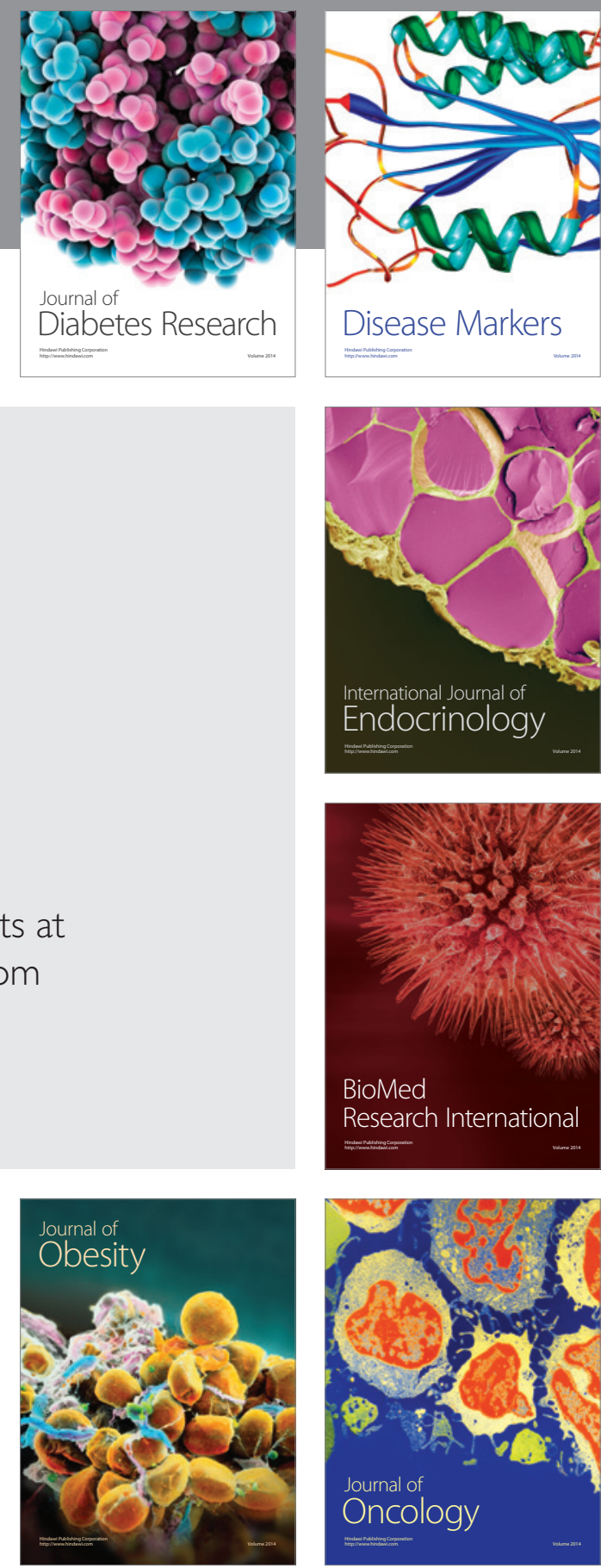

Disease Markers
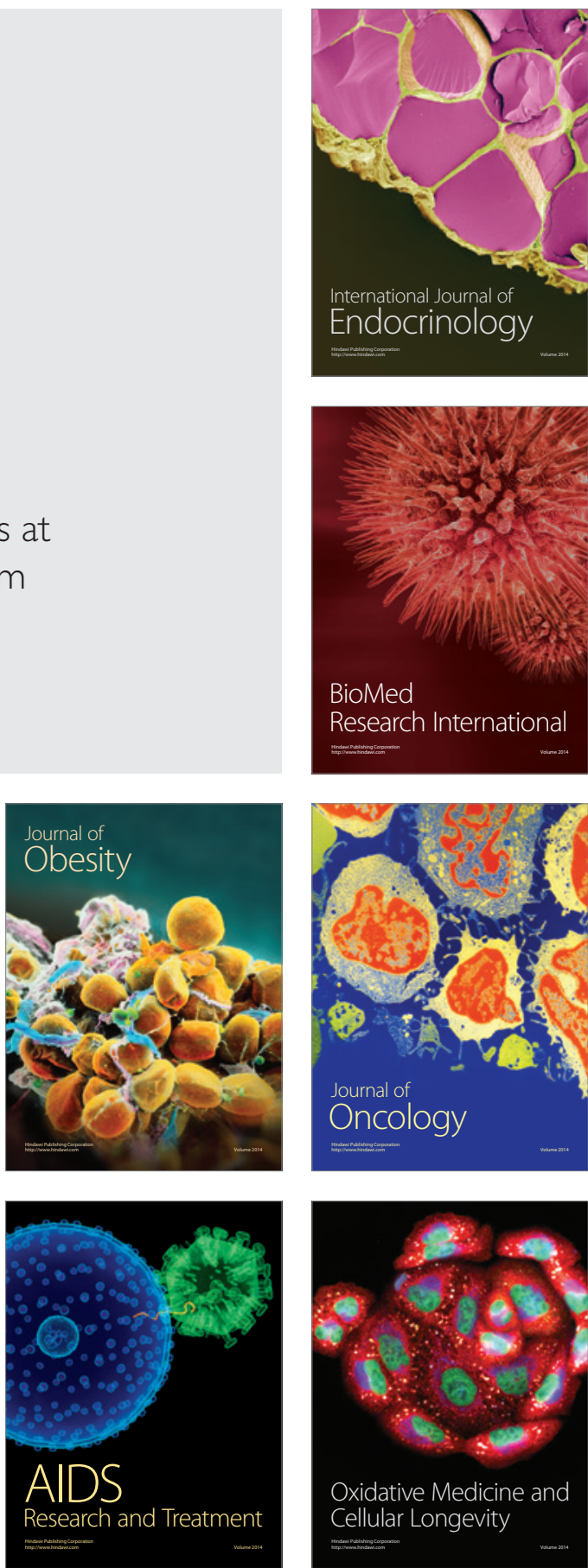